\title{
Vision of Industry 4.0
}

\author{
Wladimir Bodrow \\ Department Business Informatics \\ University of Applied Sciences Berlin \\ 10318 Berlin, Germany \\ Wladimir.Bodrow(at)htw-berlin.de
}

\begin{abstract}
This paper is devoted to concepts, approaches and some examples of the fourth industrial revolution. The basis of this revolution also well known as Industry 4.0 build so called cyber-physical systems. They contain the integrated smart software systems including the internet address to enable the communication with environment as for product itself as for means of production. All this enable the next level of efficiency and flexibility for both organizing and controlling of the valuecreation chain over the whole lifecycle of products. In the first three chapters the WEB references [1] till [8] were used. Because of multiple cross references in documents this paper is written without detailed references in each paragraph of mentioned chapters.
\end{abstract}

Keywords-fourth industrial revolution, industry 4.0, cyberphysical systems, smart production

\section{INTRODUCTION}

To understand the Forth Industrial Revolution one has to start a bit earlier. The short overview of the History is presented below.

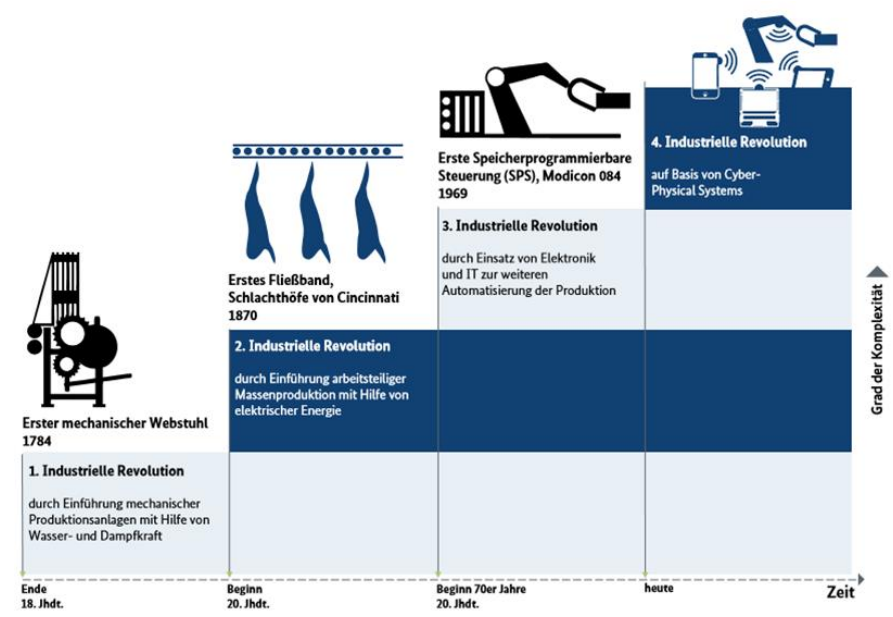

Figure 1. History of industrial revolutions (Source: Acatech Repert Industrie 4.0 in German)

The First Industrial Revolution took place at the end of $18^{\text {th }}$ century. This time began the utilization of the water power in manufacturing processes and the first steam engines appeared on the list of companies' resources. The Second Industrial Revolution is dated to the beginning of the $20^{\text {th }}$ century. The main characteristics of new industry this time were the assembly line, mass production, and the usage of electric power. The next Third Industrial Revolution came with information technology and electronic tools and applications in manufacturing at the beginning of seventies in $20^{\text {th }}$ century. Programmable logic controller (PLC) allowed increasing the operating efficiency due to the broad exploitation of programmable machines. The start point of the currently to be in progress Forth Industrial Revolution can be dated around the year 2011. The main innovation in this revolution is the implementation of new industry based on so called cyberphysical systems. Implementation of such systems provide appearance of smart Plant, smart factory, smart city, smart home, smart logistics, smart products, smart grid, etc. The main concepts and approaches utilized in corresponding applications are the condition monitoring, systems and structural health monitoring, remote diagnosis and control, tracking and tracing of processes and products.

\section{GOALS OF INDUSTRY 4.0}

The defined goal of Industry 4.0 is the implementation and utilization of individual interdependency matrix fitted to every single business process. In this respect one speaks about horizontal and vertical integration of IT-systems. The Horizontal integration covers the product life cycle from supplier till customer. It involves the design and development of product, production planning, production rump-up and management, logistics, sales and distributions. On the other side one speaks about Vertical integration of all hierarchy levels in the enterprise. This dimension comprises the enterprise planning (regarding production planning), enterprise management (regarding detailed planning, production data acquisition, and quality management), process management (regarding monitoring and management of production), and operation (regarding the interface to production process using sensors and actors).

\section{CHANGES}

The Industry 4.0 will provide the fundamental change in business including every single enterprise. There are no alternative as for large scale enterprise as for small and medium ones. The economic survival of each firm is dependent on its willingness to change. The increase of complexity and intensification of communication between all involved components are outlined in both following Figures representing the situations in Industry 3.0 and 4.0 respectively. 


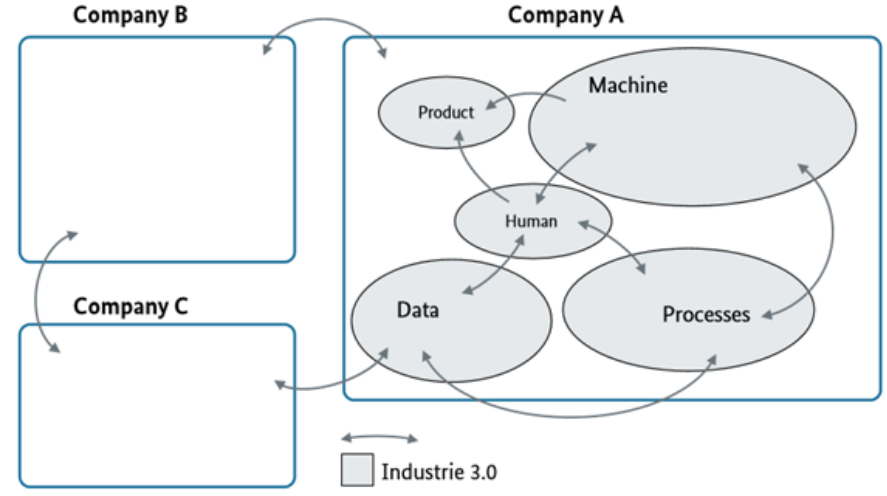

Figure 2. Communication links and trust relationships in Industrie 3.0 (Source: Platform Industrie $4.0[2,5]$ )

Company B

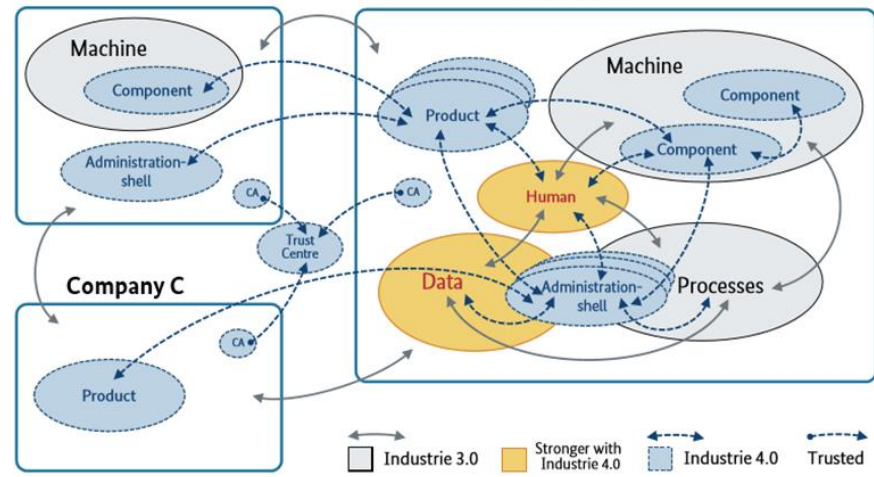

Figure 3. Communication links and trust relationships in Industrie 4.0 (Source: Platform Industrie $4.0[2,5]$ )

Below some essential changes valid for different enterprises are briefly described.

\section{A. Changes in the production}

The central point of changes in the production process is the new quality of products or components and production means or resources. All of them will be assigned to information medium with consistent data management. If needed possible they will get the individual sensor(s) and internet ID. This will enable e. g.:

- The digital value stream image and the real-time production controlling.

- Process flexibility due to the smart assistance systems.

- Online condition and energy consumption management.

- Paperless and pervasive quality assurance.

Based on these changes new perspectives for business will appear or strengthen their position on the market. The expansion directions for business are focused on:

- IT-based services like apps, sales platforms, and sales of product or service capacities.

- Innovative connectivity application e.g. for preventive maintenance or components tracking.
- New services and systems for condition monitoring, energy management, systems and structure monitoring.

- Specific sensors and actors to equip the components and production means toward the information medium and to enable their addressing, localization, and identification.

\section{B. Changes in logistic}

The essential component of Internet of things is their autonomy. The same idea is fundamental in respect to logistic in Industry 4.0. Today just all tasks related to the complexity, individuality, and changeability of both supply chain and production systems are possible to master with established (conventional) approaches and tools. Within the vision of Internet of things planning, controlling, connecting tasks are mainly delegate to employees. On the other side trucks transport the goods autonomously; cars and forklifts organize themselves based on particle swarm approach; container organize their cargo and exchange with others in the logistic net; boxes communicate which parts hasto be removed and organize their replenishment.

\section{Influence of Big Data and Cloud}

Big Data is one of enabler and motor of forth industrial revolution. Enterprise wide utilization of sensor technology and digitalization of data acquisition provide the analysts and decision maker with information regarding every activity and thing in each business process. The storage of this data in the cloud will enable its accessibility and processing anytime everywhere. Using the predictive applications based on various statistical and analytical approaches management can investigate the expectable events and optimize the business processes. The overview of the Cloud and Big Data utilization is presented in the Fig. 4.

\section{SensorCloud}

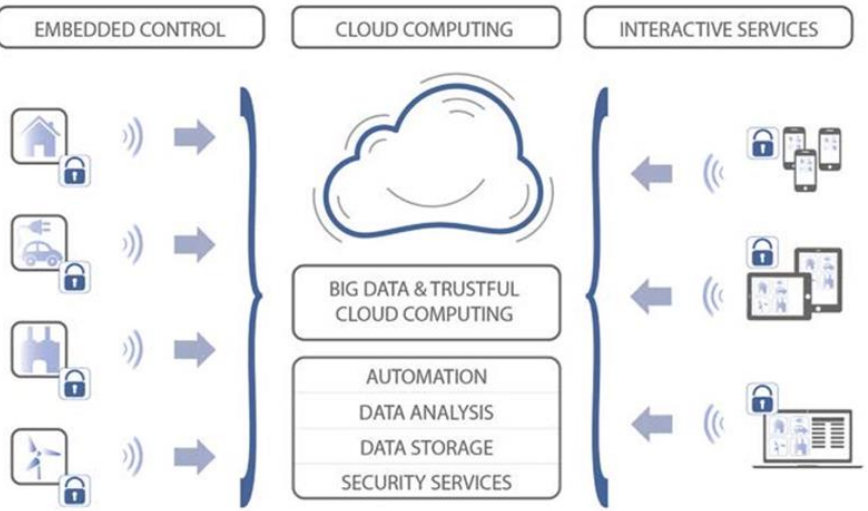

Figure 4. The Role of Cloud Computing and Big Data in Industrie 4.0 (Source RWTH Aachen)

\section{BUSINESS CASE}

\section{A. Project environment}

Selected business project was realized in cooperation one car repair shop. The firm represents a medium size enterprise 
with ca. 30 employees. Most of them are technicians and direct involved in repair service. The firm facilities contain eight boxes equipped with different machines and tools.

\section{B. Project goals}

During the discussion with foreman and administration some problem areas and tasks were localized. The project team concentrates first on efficient usage of production means. The outgoing points are:

- There exist only few computer-based diagnostic instruments.

- Some of technicians are not qualified and work with the old equipment also available in the firm.

- Every day several times occurs the period of peak activity regarding one or another machine and certified technicians.

- Other time the machines are not in use.

- Management considers the possible alternatives to further investment in machines and tools.

- $\quad$ Space required for the machines play also a role within a decision.

Defined goal after the project implementation was the better usage of production means and enhanced planning of personal. Every technician and administration has to be enabled to communicate to customer the sequence and timing of the repair activities.

\section{Feasible changes in process}

Project has to improve the efficient usage of all resources including machines, tools and the personal planning according to individual qualification and skill. The main advantage will be expected through the implementation of agile planning based on Online Analytical Processing and utilization of results. Analysis of the exploitation of resources has to be used for improvement of the efficiency and effectivity of the process and get appropriate suggestions for its change. Management will use the result to make a decision about next investments and qualification activities.

\section{Realization concept and implementation}

All machines in the firm were equipped with sensors, got their ID and connection to the WEB server. Employees received the smartphone with installed connection to the server and personal dashboard. All machines report to server their current and planned usage by particular employee and localization. If single technician demands some kind of service with special machine or tool the information will be communicated to the planning application installed on server to check the position, application, and availability of machine and plan the next activity. The same procedure will be carried out regarding the demand of professional knowledge and skill by technicians.
The usage of the machines and tools will be analyzed every month to improve the planning and to make the personal and investment decisions by management.

\section{E. Feedback and future activities}

- Implemented solution allows the high level of flexibility and transparency in planning of repair activities.

- Main conflicts the project team has had with employees regarding the involvement of machines into the decision making process.

- Implemented rules for the planning suggestions were not optimal according to employees not involved in the project.

- Implemented dashboards will be improved regarding the information transparency.

- The button for input of alternative suggestions will be integrated in the interface.

The results achieved will be used for further research and development projects in cooperation with small and medium size enterprises to utilize the acquired skill and competency in the business practice. This will go in line with the Reference Architecture Model Industrie 4.0 defined in [3] and outlined below.

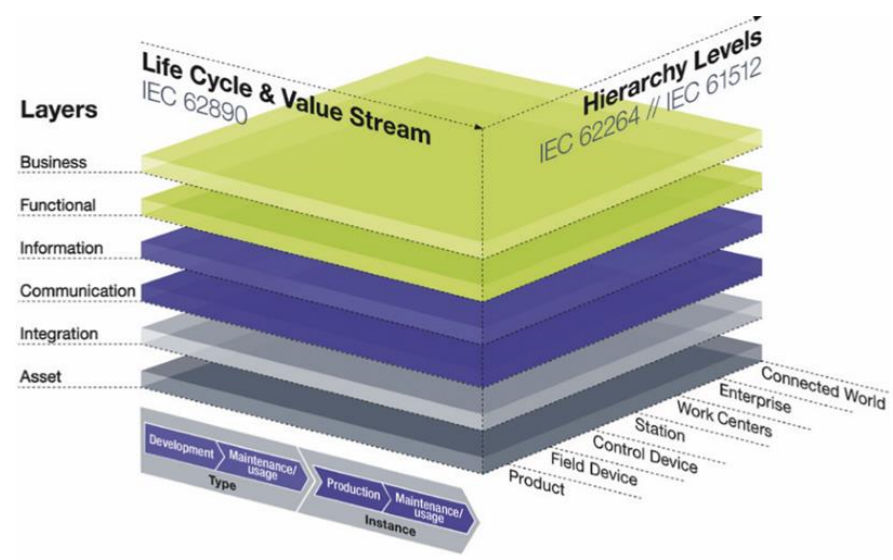

Figure 5. Reference Architecture Model Industrie 4.0 (RAMI 4.0, Source [3] p. 43).

\section{REMARK ABOUT AVAILABLE PUBLICATIONS}

In presentation some videos accessible on the WEB and referenced below from [9] till [20] were used. This was done because of the quality of materials available. Additionally to mentioned WEB publications [1 - 8] from different granted projects there appeared several books devoted different aspects of Industrie 4.0 [21 - 29]. They provide the overview about the realization of the industrial implementation concepts and approaches in the German companies.

\section{REFERENCES}

[1] https://www.bmbf.de/de/zukunftsprojekt-industrie-4-0-848.html German)

[2] http://www.plattform-i40.de/I40/Navigation/EN/Home/home.html 
[3] BITKOM e.V., VDMA e.V., ZVEI e.V. (Eds.) "Umsetzungsstrategie Industrie 4.0", Berlin, April 2015

[4] "Aspects of the Research Roadmap in Application Scenarios" Working paper, Federal Ministry for Economic Affairs and Energy (BMWi) Public Relations, April 2016

[5] "Digitization of Industrie - Plattform Industrie 4.0" Prograss report, Federal Ministry for Economic Affairs and Energy (BMWi) Public Relations, April 2016

[6] "Interaction Model for Industrie 4.0 Components", Federal Ministry for Economic Affairs and Energy (BMWi) Public Relations, March 2016

[7] “Technical Overview: Secure cross-company communication”, Working paper, Federal Ministry for Economic Affairs and Energy (BMWi) Public Relations, April 2016

[8] „Industrie 4.0 Research at German Research Institutes - An Overview“, VDMA, April 2016

[9] https://www.youtube.com/watch? $v=d k d d S a O O Z c s$

[10] https://www.youtube.com/watch?v=HPRURtORnis

[11] https://youtu.be/PMEoav353J8

[12] https://www.youtube.com/watch?v=JT18w6yAjds

[13] https://www.youtube.com/watch?v=Y990kaGbJD0

[14] https://www.youtube.com/watch?v=ISk64bJ35yM

[15] https://www.youtube.com/watch?v=MZkY9HNCiM0

[16] https://www.youtube.com/watch?v=GKhSTjraHIU

[17] https://www.youtube.com/watch?v=DrE0FShBfF4

[18] https://www.youtube.com/watch?v=XZF10XrowGU
[19] https://www.youtube.com/watch?v=NIyyb5Jj7tk

[20] https://www.youtube.com/watch?v=Z9jSudu0oHo

[21] T. Bauernhansl, M. Ten Hompel, B. Vogel-Heuser (Hrsg.): Industrie 4.0 in Produktion, Automatisierung und Logistik., Wiesbaden, 2014 (in German)

[22] A. Syska, Ph. Lièvre: Illusion 4.0 - Deutschlands naiver Traum von der smarten Fabrik, Herrieden, 2016 (in German)

[23] W. A. Halang, H. Unger: Industrie 4.0 und Echtzeit, Springer Vieweg, 2014 (in German)

[24] Herausgeber: Roth, Armin (Hrsg.) Einführung und Umsetzung von Industrie 4.0 Grundlagen, Vorgehensmodell und Use Cases aus der Praxis, Springer Gabler 2016 (in German)

[25] R. Obermaier, (Hrsg.) Industrie 4.0 als unternehmerische Gestaltungsaufgabe Betriebswirtschaftliche, technische und rechtliche Herausforderungen, Springer Gabler 2016 (in German)

[26] Th. Bauernhansl, M. ten Hompen, B. Vogel-Heuser (Hrsg.): Industrie 4.0 in Produktion, Automatisierung und Logistik: Anwendung . Technologien · Migration, Springer Vieweg, 2014 (in German)

[27] T. Kaufmann: Geschäftsmodelle in Industrie 4.0 und dem Internet der Dinge: Der Weg vom Anspruch in die Wirklichkeit Springer Vieweg, 2015 (in German)

[28] Ch. Köhler-Schute (Hrsg.) Industrie 4.0: Ein praxisorientierter Ansatz Gebundene Ausgabe KS-Energy-Verlag 2015 (in German)

[29] Ch. Manzei, L. Schleupner, R. Heinze: Industrie 4.0 im internationalen Kontext: Kernkonzepte, Ergebnisse, Trends VDE Verlag 2015 (in German) 